Dr. Nicholas R. Bates

Senior Research Scientist

Bermuda Institute of Ocean Sciences (BIOS), 17 Biological Station Lane, Ferry Reach, GE01, Bermuda email: nick.bates@bios.edu; phone: (441) 297-1880x209

December 02, 2013

Editors

Biogeosciences

\title{
Re: Submission of manuscript bg-2013-605
}

To the Editors

We have submitted the following paper to Biogeosciences, entitled "Sea-ice melt $\mathrm{CO}_{2}$-carbonate chemistry in the western Arctic Ocean: Meltwater contributions to air-sea $\mathrm{CO}_{2}$ gas exchange, mixed layer properties and rates of net community production under sea ice" (bg-2013-605), by N.R. Bates, R. Garley, K.E. Frey, K.L. Shake and J.T. Mathis.

The paper reports on recent observations of the sea-ice melt water $\mathrm{CO}_{2}$-carbonate chemistry of seaice melt pond water in the western Arctic Ocean. The melt pond, and co-located mixed layer biogeochemistry data was collected at nineteen sea-ice stations between 2010 and 2011 (northern Chukchi Sea and southern Canada Basin) during the NASA sponsored ICESCAPE project. The paper is primary focused on the $\mathrm{CO}_{2}$-carbonate chemistry of above-ice melt ponds, meltwater-influenced interface between sea-ice and mixed layer. We report the dissolved inorganic carbon and total alkalinity (and associated $p \mathrm{CO}_{2}, \mathrm{pH}$ and saturation states aragonite $\left(\Omega_{\text {aragonite }}\right)$. Meltwater $\mathrm{CO}_{2}$-carbonate chemistry is highly variable, ranging from acidic ( $\mathrm{pH}$ of $\sim 6$ ) to alkaline ( $\mathrm{pH}$ of $\sim 10)$, and $p \mathrm{CO}_{2}$ ranged from very low to $1500 \mathrm{ppm}$. As a context for the paper, it should be noted that very few studies have been conducted on sea-ice $\mathrm{CO}_{2}$-carbonate chemistry, and even fewer on melt pond water.

We also discuss the potential role of meltwater for air-sea $\mathrm{CO}_{2}$ gas exchange, and how meltwater complicates the determination of the rates of net community production (NCP) in the mixed layer beneath sea-ice. Melt ponds, transient seasonal phenomena as they are, potentially contribute to the complex drivers of air-sea $\mathrm{CO}_{2}$ gas exchange in the Arctic Ocean and recent changes in $\mathrm{CO}_{2}$ fluxes (e.g., see relevant papers by Bates et al., 2006; Bates and Mathis, 2009; Cai et al., 2010; Schuster et al., 2013; Manizza et al., 2013). Melt pond chemistry also contributes substantively to determination of NCP, and contributes to enhancement/amelioration of ocean acidification in the Arctic Ocean (e.g., in the western Arctic; see relevant papers by Orr et al., 2005; Steinacher et al., 2010; Bates et al., 2009; 2013).

The paper is not under consideration elsewhere. The first author was primarily responsible for writing of the manuscript and data synthesis and interpretation.

Yours truly

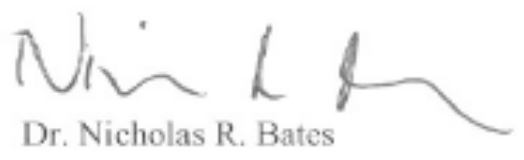

Associate Director of Research and Senior Research Scientist 